\title{
Faecal chymotrypsin: a reliable index of exocrine pancreatic function
}

\author{
G A BROWN, D SUlE, J WILliaMs, J W L PUNTIS, I W BOOTH, AND A S McNEISH
}

Institute of Child Health, University of Birmingham, Birmingham

SUMMARY Simultaneous measurements of duodenal and faecal chymotrypsin were made in 30 children aged 3 weeks to 14 years. Apparent chymotrypsin secretion rates measured after stimulation with pancreozymin were compared with the mean faecal chymotrypsin concentration derived from three stool specimens collected at random within 72 hours of the intraduodenal test. In the 25 children who responded to pancreozymin stimulation the mean faecal chymotrypsin concentration was significantly positively correlated with the apparent chymotrypsin secretion rate. Correlation using single specimen stools collected at random was appreciably poorer. In the five children with undetectable or only traces of chymotrypsin in the duodenum after stimulation, the mean faecal chymotrypsin concentrations were only $3-10 \%$ of the lower limit of the reference interval. In a second group of 46 children with cystic fibrosis proved by sweat tests and clinical evidence of malabsorption, the chymotrypsin concentration measured in a single stool specimen collected at random was unequivocally subnormal in each case.

Faecal chymotrypsin measurement is a rapid, simple, cheap, readily repeated, non-invasive test of high specificity and sensitivity. Faecal chymotrypsin should be measured before contemplating intraduodenal tests of pancreatic function.

In routine clinical practice pancreatic exocrine function is most accurately assessed by measuring the products of pancreatic secretion in fluid from the upper small intestine. ${ }^{1}$ Tests requiring intubation of the intestine are, however, technically difficult, expensive, and invasive and there have been many attempts to find an alternative, particularly for the investigation of children. One approach-the measurement of pancreatic proteolytic enzymes in faeces using pancreatic enzyme specific substrateshas been available for many years ${ }^{2}$ but there is still a lack of concensus about its value. Measurement of faecal chymotrypsin has been recommended by some workers ${ }^{34}$ but other paediatric gastroenterologists discourage it, ${ }^{56}$ and a firm theoretical basis is required to justify further use of the test. We have therefore sought to validate measurement of faecal chymotrypsin by investigating its performance in two ways: firstly by correlating the results with the activities of chymotrypsin and trypsin in the duodenum after stimulation with pancreozymin and secretin, and secondly by measuring its ability to identify the defect in known cases of pancreatic exocrine insufficiency.

\section{Subjects and methods}

To investigate the correlation between enzyme activities in faeces and duodenal fluid we studied 30 children who were having intraduodenal pancreatic function tests for investigation of gastrointestinal symptoms. Their ages ranged from 3 weeks to 14 years (median 21 months) and weights ranged from 1.8 to $35 \mathrm{~kg}$ (median 8.6). Of five children who failed to secrete enzyme after stimulation with pancreozymin and secretin two had ShwachmanDiamond syndrome, one had had a resection of pancreas for nesidioblastosis, one had a pancreatic pseudocyst, and in one the aetiology was unknown. One child with partial insufficiency had inflammatory bowel disease with malnutrition. The remaining 24 children were considered to have normal pancreatic function after investigation.

To investigate the ability of the test in patients known to have pancreatic exocrine insufficiency we studied 46 children with cystic fibrosis proved by raised concentrations of electrolytes in the sweat, and clinical evidence of malabsorption. 
INTRADUODENAL PANCREATIC FUNCTION TESTS

After fasting and sedation with chlorpromazine the children were intubated with a 12 FG nasoduodenal tube that had been modified by removing the end and adding side holes. The tip of the tube was placed at the duodenojejunal flexure under radiographic control. Contamination of duodenal fluid with gastric fluid was prevented by frequently aspirating the stomach through a nasogastric tube. Full details of the technique are given by Tripp et al. ${ }^{7}$

The pancreatic function tests were done by a technique similar to that of Hadorn. ${ }^{8}$ Fluid was collected by suction over two 10 minute basal secretion periods. Pancreozymin was given intravenously ( $2 \mathrm{U} / \mathrm{kg}$ body weight) and a further two 10 minute fluid collections were then made. This was followed immediately by an intravenous injection of secretin ( $2 \mathrm{U} / \mathrm{kg}$ body weight), and fluid collection was continued for a further three 10 minute periods. Each fluid specimen was placed in a vacuum flask with solid carbon dioxide immediately after collection.

In the laboratory, fluids were kept at $-20^{\circ} \mathrm{C}$. Chymotrypsin and trypsin were measured within 24 hours of the completion of the test. The duodenal fluid was analysed without any preparation except centrifugation at $3000 \mathrm{~g}$ for 10 minutes at $4^{\circ} \mathrm{C}$ to remove insoluble material. Enzyme activities were measured in each 10 minute fluid specimen. Mean concentrations were calculated for the five specimens collected after stimulation with pancreozymin. Secretion rates were calculated by adding the content of the same five specimens and expressing the result as a proportion of body weight. The sampling procedure may have resulted in the loss of some part of the enzyme secreted, so secretion rates were designated 'apparent secretion rate'.

\section{STOOL COLLECTION AND PREPARATION}

For the $\mathbf{3 0}$ children in the first part of the study, three specimens of stool weighing 1-2 g were collected at random on three separate days within 72 hours of the intraduodenal pancreatic function test. Stool analyses were done on samples diluted 1/7 $\mathrm{w} / \mathrm{w}$. About $.0 \cdot 5 \mathrm{~g}$ stool was first homogenised $1 / 3$ w/w with water using a Potter-Elvehjem pattern glass and Teflon homogeniser with $0.1 \mathrm{~mm}$ clearance for maximum dispersion of stool solids. This homogenate was diluted with an equal volume of $0.01 \mathrm{M}$ TRIS buffer, $\mathrm{pH} 7 \cdot 8$, to produce a final stool dilution of $1 / 7 \mathrm{w} / \mathrm{w}$. Chymotrypsin activity is adsorbed to the solid phase of faecal homogenates, so care was taken to prepare extremely fine homogenates and to mix them thoroughly before sampling for analysis.

For the 46 children with cystic fibrosis and clinical malabsorption a single stool specimen was collected at random before starting replacement of pancreatic enzymes, or after withdrawal of enzymes replacement for a minimum of 72 hours before stool collection.

\section{ENZYME MEASUREMENTS}

Chymotrypsin (EC 3.4.21.1) and trypsin (EC 3.4.21.4) were measured by kinetic, potentiometric methods, ${ }^{2}$ in which the rate of hydrolysis of enzyme specific, synthetic substrates (acetyl tyrosine ethyl ester and benzoyl arginine ethyl ester for chymotrypsin and trypsin, respectively) was recorded with an automatic titrator and recorder (Radiometer, Copenhagen). The chymotrypsin and trypsin concentrations were determined using bovine $\alpha$ chymotrypsin (Sigma C4129) and trypsin (Sigma T8642) for the reference standards. The precision of the faecal chymotrypsin analysis was determined by duplicate analysis of 30 faecal samples covering the range $120-1400 \mu \mathrm{g} / \mathrm{g}$ stool. The coefficient of variation was $5 \cdot 8 \%$. The recovery of $25 \mu \mathrm{g}$ bovine chymotrypsin added to 14 separate faecal homogenates ranged from $90 \cdot 6-107 \cdot 8 \%$ with a mean recovery of $99.2 \%$.

The bovine $\alpha$ chymotrypsin reference standard had an activity of $0.17 \mathrm{U} / \mu \mathrm{g}$, the unit being the activity that hydrolysed $1 \mu \mathrm{mol}$ of acetyl tyrosine ethyl ester in one minute under the conditions described for the method.

\section{Results}

\section{DUODENAL FLUID ENZYMES}

Of the 30 children studied, 25 responded to the pancreozymin stimulation. Twenty four had apparent trypsin secretion rates above the lower limit of the control range that was defined by Hadorn ${ }^{8}$ and confirmed in this department (fig 1), and one was below. In the remaining five tests, the apparent trypsin secretion rates were grossly subnormal with no enzyme activity detectable in three and traces only in two.

The apparent chymotrypsin secretion rates were segregated in the same way. The five children who failed to produce a trypsin response after stimulation with pancreozymin also failed to produce a chymotrypsin response. The child that produced a measurable but subnormal apparent trypsin secretion rate also had a subnormal apparent secretion rate of chymotrypsin of only $30 \%$ of the lower limit (mean minus $2 \mathrm{SD}$ ) of the 24 normal responders. The results of analysis of duodenal fluid therefore ranged from grossly subnormal through partial insufficiency to the physiological range, thereby providing a wide 


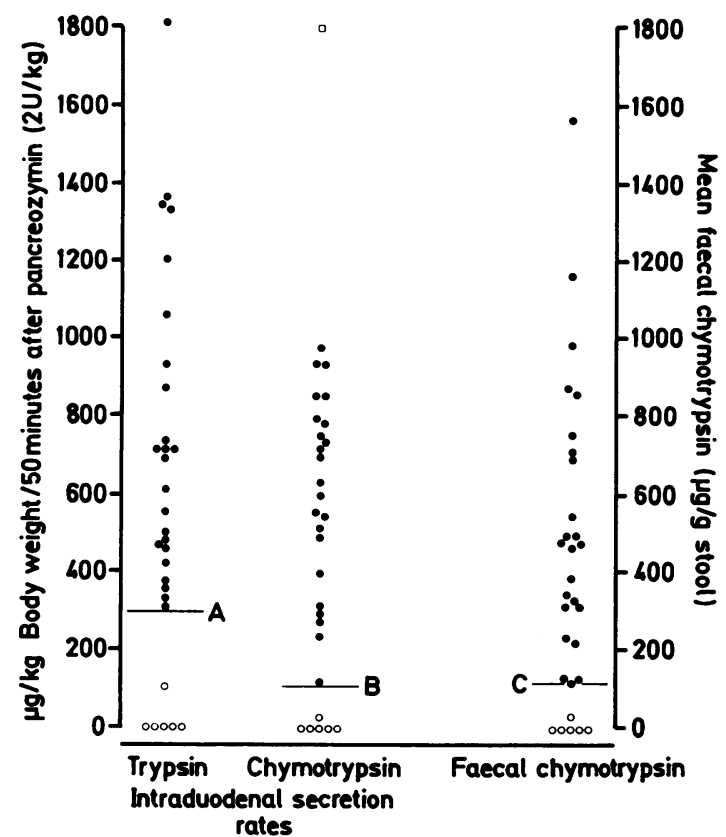

Fig 1 Apparent rates of secretion for trypsin and chymotrypsin in 30 intraduodenal tests compared with mean faecal chymotrypsin concentrations. Segregation was identical by all three measurements. $A=$ mean minus $2 S D$ for control subjects ${ }^{8} ; B=$ mean minus $2 S D$ of data presented but omitting the highest value that was more than $3 S D$ above the mean; mean (indicated by an open square); $C=$ lower limit of observed range from 150 stool specimens collected at random from 25 healthy infants. $=$ patients with normal response to pancreozymin stimulation, and $\mathrm{O}=$ patients with pancreatic insufficiency.

range for identification of a correlation between enzyme activities in duodenal juice and faeces.

\section{FAECAL CHYMOTRYPSIN CONCENTRATIONS}

The mean faecal chymotrypsin concentrations were segregated in the same way as the activities in duodenal juice (fig 1). In the five patients with absent or only a trace of duodenal chymotrypsin and trypsin after stimulation, faecal chymotrypsin was also extremely low or absent. The highest mean chymotrypsin in this group was $12 \mu \mathrm{g} / \mathrm{g}$ stool, which was only $10 \%$ of the lower limit of our reference range $(120 \mu \mathrm{g} / \mathrm{g}$ stool $)$. Of the 25 children with measurable duodenal enzyme activities, 24 had mean faecal chymotrypsin concentrations of 120 $\mu \mathrm{g} / \mathrm{g}$ stool or greater. The one child in this group whose results were low $(40 \mu \mathrm{g} / \mathrm{g}$ stool, $33 \%$ of the lower limit of our reference range) had the subnor- mal but measurable apparent secretion rates of trypsin and chymotrypsin already mentioned.

\section{CORRELATION BETWEEN DUODENAL ENZYME ACTIVITIES} AND FAECAL CONCENTRATIONS

In the 25 children who produced measurable enzyme activities in the duodenum after stimulation, mean faecal chymotrypsin concentration showed a highly significant positive correlation with apparent secretion rates of chymotrypsin (fig 2). The Spearman rank correlation coefficient was $0.63(\mathrm{p}<0.001)$. When the apparent secretion rates of chymotrypsin were correlated with chymotrypsin concentrations from single stool specimens collected at random (the initial stool from each triplicate), the correlation only just reached significance $(r=0.43, p<0.05$, $>0.025$ ). Significant positive correlations were also shown between mean faecal chymotrypsin concentration and mean duodenal chymotrypsin concentration, and also between mean faecal chymotrypsin concentration and the apparent secretion rates of trypsin, but the degree of association measured by the Spearman rank correlation coefficient values was less for both correlations (correlation coefficients 0.45 and 0.48 respectively, $\mathrm{p}<0.01$ ).

Using the lower limit of the range of control apparent secretion rates for trypsin or chymotrypsin and the lower limit of the faecal chymotrypsin reference range to define the boundary between normal and abnormal pancreatic function, none of

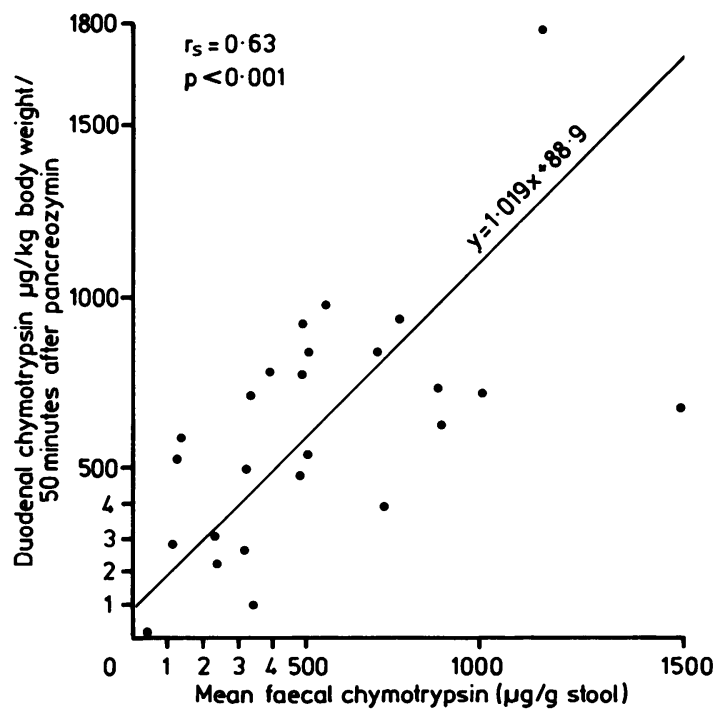

Fig 2 Correlation of apparent secretion rates of chymotrypsin with mean faecal chymotrypsin concentrations. 
the children produced inconsistent results from either source.

\section{PATIENTS WITH PANCREATIC INSUFFICIENCY}

In the 46 children with cystic fibrosis and clinical malabsorption faecal chymotrypsin was absent in 16 , and in the remaining 30 concentrations were $60 \%$ $(72 \mu \mathrm{g} / \mathrm{g}$ stool) or less of the lower limit of our reference range. The median concentration was 6 $\mu \mathrm{g} / \mathrm{g}$ stool, or $5 \%$ of the lower limit of the reference range.

\section{Discussion}

In the study correlating duodenal enzyme activities and faecal concentrations, mean faecal chymotrypsin concentrations derived from three separate stool specimens collected at random within 72 hours of the intraduodenal test were highly significantly correlated with the apparent secretion rates of chymotrypsin. The correlation applied whether pancreatic function was compromised or within the physiological range, with the result that the segregation in the apparent secretion rates of chymotrypsin between normal pancreatic function and pancreatic insufficiency was reproduced identically by the mean faecal chymotrypsin concentrations. In the 46 children with cystic fibrosis and clinical evidence of malabsorption faecal chymotrypsin concentrations were without exception grossly subnormal.

Various measures of correlation have been reported in adults between: duodenal output of chymotrypsin and output in 24 hour stool collections ${ }^{9}$; duodenal output of trypsin and chymotrypsin concentrations in stool specimens collected at random ${ }^{10}$; and duodenal concentration of chymotrypsin and faecal concentration. ${ }^{11}$ None, however, correlated chymotrypsin secretion rates with chymotrypsin concentration in stool specimens collected at random-the only specimens that are readily available in infants and young children. There have been no correlation studies reported in children.

It was necessary to use multiple faecal analyses to achieve the degree of association between duodenal and faecal measurements that we have shown. Using only the results from the first of the three stool analyses for correlation produced a significantly lower degree of association. Homogeneity of chymotrypsin distribution has been claimed both within the individual stool ${ }^{12}$ and between three stool specimens collected at random on separate days. ${ }^{11}$ This may be what usually happens, but our experience has been that the occurrence of comparatively unrepresentative results from analysis of a single stool specimen is sufficiently frequent to make multiple analyses essential. Four of the 75 individual stool analyses in the correlation study differed by more than $50 \%$ (median value $=14 \%$ ) from the mean value of their relevant triplicates, and the largest deviation was $84 \%$. Such differences are quite large enough to give rise to misinterpretation of single results at the lower limit of the reference range.

Other workers have also emphasised this point, recommending the use of two $^{10}$ or more $\mathrm{e}^{13}$ stool specimens collected at random. Moeller ${ }^{13}$ found three of 22 faecal chymotrypsin results from nine adults with pancreatic exocrine insufficiency within their control range. By repeat testing and using mean values all false negatives were eliminated. We recommend the use of three specimens collected at random. If all three stool specimens produce chymotrypsin concentrations significantly greater than the lower limit of the reference range, pancreatic insufficiency at the time of the investigation can be excluded. This would not be true for specific lipase, co-lipase, or trypsinogen deficiencies but these conditions are extremely rare.

In the $\mathbf{4 6}$ children with cystic fibrosis and clinically recognised malabsorption, faecal chymotrypsin concentrations were unequivocaily subnormal, and single stool specimens were sufficient to identify the gross pancreatic insufficiency characteristic of the disease. The children were selected for the present study because they had malabsorption and it was not considered ethically justifiable to confirm the degree of pancreatic insufficiency by intubation and hormone stimulation.

Controversy persists over the efficiency of faecal chymotrypsin measurement as a method of assessing pancreatic function because of confusion over the function and capability of the test. The test may not detect the initial stages of insufficiency in developing disease. It cannot differentiate between normal pancreatic function and chronic pancreatitis where secretion (though invariably ultimately compromised) may initially be normal, and pancreatic carcinoma where reduced secretion (if it occurs) depends on the site and nature of the lesion. The reputation of the test has suffered because it does not resolve these 'adult' problems.

In addition to the difference in the clinical questions being asked, there may be other reasons for greater specificity in children. Mean whole gut transit times are shorter in children, the transit time of the neonate ${ }^{14}$ being about a quarter of that of the adult. ${ }^{15}$ The shorter transit time reduces the opportunity for bacterial ${ }^{16}$ and enzymatic ${ }^{17}$ degradation in transit, making the test more direct and increasing its specificity. Reducing adult whole gut transit time with purgatives to about that of the neonate improves the duodenal faecal chymotrypsin correlation. ${ }^{9}$ 
In addition to the high sensitivity and specificity, assessing pancreatic function by faecal chymotrypsin measurements has much to recommend it in children. It is completely non-invasive, does not entail oral dosing and requires little cooperation on the part of the patient, except for stool retention. The quantity of faeces needed is too small to give offence in or outside the laboratory or to present the latter with problems of microbiological containment of potentially hazardous material. The procedure is simple, cheap, and rapid compared with other methods of measuring pancreatic function. These features make the test repeatable as often as necessary so that confirmation by repeat testing is always possible and longitudinal studies requiring frequent repeat tests are also possible.

A further advantage of chymotrypsin is its stability at ambient temperatures in the United Kingdom. Little loss of activity occurs after it has been standing at $18^{\circ} \mathrm{C}$ for 72 hours, so that specimens may be sent by post with confidence and without any special provision other than secure packing and avoiding weekends.

Intraduodenal testing will continue to be necessary to identify the rare, specific deficiencies of pancreatic enzymes, but in most children in whom pancreatic exocrine functions is questioned the answer should be sought first by measuring faecal chymotrypsin concentrations.

\section{References}

' DiMagno EP. Diagnosis of chronic pancreatitis: arc noninvasive tests of exocrine pancreatic function sensitive and specific? Gastroenterology 1982;83:143-6.

2 Haverback BJ. Dyce BJ, Gutentag PJ, Montgomery DW. Measurement of trypsin and chymotrypsin in stool: a diagnostic test for pancreatic exocrine insufficiency. Gastroenterology 1963:44:588-97.

${ }^{3}$ Barbero GJ, Sibenga MS, Marino JM, Scibel R. Stool trypsin and chymotrypsin: value in the diagnosis of pancreatic insufficiency in cystic fibrosis. Am J Dis Child 1966;112:536-40.
${ }^{4}$ Scotta MS, Marzani MD, Maggiore G, De Giacomo C, Melzi d'Eril GV, Moratti R. Fecal chymotrypsin: a new diagnostic test for exocrine pancreatic insufficiency in children with cystic fibrosis. Clin Biochem 1985;18:233-4.

${ }^{5}$ Packer SM, Milla PJ, Tripp JH. Investigatory techniques. In: Harries JT, ed. Essentials of paediatric gastroenterology. Edinburgh: Churchill Livingstone, 1977:38-60.

${ }^{6}$ Tripp JH, Muller DPR. The gastrointestinal tract. In: Clayton $\mathrm{BE}$, Round JM, eds. Chemical pathology and the sick child. Oxford: Blackwell Scientific Publications, 1984:150-75.

7 Tripp JH, Candy DCA. Manual of paediatric gastroenterology. Edinburgh: Churchill Livingstone, 1985.

${ }^{8}$ Hadorn B. The exocrine pancreas. In: Anderson CM, Burke V, eds. Paediatric gastroenterology. Oxford: Blackwell Scientific Publications, 1975:289-328.

${ }^{9}$ Sale JK, Goldberg DM, Thjodleifsson B, Wormsley KG. Trypsin and chymotrypsin in duodenal aspirate and faeces in response to secretin and cholecystokinin-pancreozymin. Gut 1974; 15:132-8

10 Durr HK, Otte M, Forell MM, Bode JC. Fecal chymotrypsin: a study on its diagnostic value by comparison with the secretincholecystokinin test. Digestion 1978;17:404-9.

1 Lami F, Callegari C, Miglioli M, Barbara L. A single fecal chymotrypsin test in the diagnosis of pancreatic insufficiency: correlation with secretin-cholecystokinin and NBT-PABA tests. Am J Gastroenterol 1984;79:697-700.

12 Kaspar P, Newmann U. The distribution of chymotrypsin within the feces and description of a new device for the preparation of stool samples. Clin Chem 1984;30:1864-6.

13 Moeller DD, Dewey Dunn G, Klotz AP. Diagnosis of pancreatic exocrine insufficiency by fecal chymotrypsin activity. $\mathrm{Am} \mathrm{J}$ Dig Dis 1973;18:792-6.

14 Rubaltelli FF, Largajolli G. Effect of light on gut transit time in jaundiced newborns. Acta Paediatr Scand 1973;62:146-8.

15 Cann PA, Read NW, Brown C, Hobson N, Holdsworth CD. Irritable bowel syndrome: relationship of disorders in the transit of a single solid meal to symptom patterns. Gut 1983;24:405-11.

16 Borgstrom A. Genell S, Ohlsson K. Elevated fecal levels of endogenous pancreatic endopeptidases after antibiotic treatment. Scand J Gastroenterol 1977;12:530-45.

17 Layer P, Go VLW, DiMagno EP. Fate of pancreatic enzymes during small intestinal aboral transit in humans. Am J Physiol 1986;251:G475-80.

Correspondence to Mr GA Brown, Institute of Child Health, Francis Road, Birmingham B16 8ET.

Accepted 22 February 1988 